\title{
MJN \\ EFFECTIVENESS OF INHALATION OF LAVENDER OIL IN RELIEVING POST-CESAREAN SECTION PAIN
}

\author{
Ragaa Ali Abdraboo ${ }^{1}$, Hadayat AbdEI-Raof Amasha ${ }^{2 *}$, Sally Ebrahim Ali ${ }^{3}$ \\ ${ }^{1}$ Maternal \& Newborn Health Nursing, Faculty of Nursing, Cairo University, Egypt \\ ${ }^{2}$ Maternal Health Nursing and Newborn, Faculty of Nursing, Damietta University, Egypt \\ ${ }^{3}$ Governmental Hospital, El-Manzala, Egypt \\ *Corresponding Author’s Email: drtotoa67@yahoo.com
}

\begin{abstract}
Background: Lavender proved to be effective in relieving pain arising from many conditions. However, there is a paucity of studies addressing its effectiveness in the relief of post-cesarean section (CS) pain. Aim: to investigate the effectiveness of inhalation of Lavender oil in relieving post-CS pain. Subjects and methods: This quasi-experimental controlled study was carried at the Postpartum Unit affiliated to Suez-Canal University Hospitals on a convenience sample of 100 postpartum women delivered by CS. They were randomly divided into two equal groups, 50 receiving Lavender oil and oxygen, and 50 control. An interview questionnaire sheet with the Visual Analogue Scale (VAS), and the Modified Version of Johansson Pain-O-Meter (MJPOM) pain scale was used to collect data. The work was from October 2013 to January 2014. Results: Women in the two groups had similar demographic and obstetric characteristics. The mean VAS pain score was almost double in the control group compared with the study group $(p<0.001)$. Moreover, the mean MJPOM pain scores (sensory, affective, and total) were all higher in the control group $(p<0.001)$. Pain scores were higher among primiparas $(p<0.001)$, and $68.0 \%$ of study group women reported that Lavender was effective in decreasing their post-CS pain. Conclusion and recommendations: Lavender oil inhalation is effective in relieving post-CS pain. A duplication of this study using a full randomized clinical trial design is recommended to provide a stronger evidence of its effectiveness and to overcome the limitations of the quasi-experimental design concerning internal validity.
\end{abstract}

Keywords: Lavender, Cesarean section, VAS, MJPOM

\section{INTRODUCTION}

Complementary and alternative therapies are gaining increasing importance in health care. They include a variety of non-pharmacological approaches such as acupressure or acupuncture, aromatherapy, hypnotherapy, massage, reflexology, etc. Research shows improvements among patients receiving such therapies compared with controls (Zeng et al., 2018). Aromatherapy refers to the use of volatile oils or aroma compounds, which are concentrated products extracted from natural plants through steam distillation. They can be used through skin application as an ointment, oral intake, or inhalation. Their side effects are often rare and minimal such as allergic reactions or overdose (Steflitsch, 2017).

Lavender essential oil is distilled from the plant Lavandula angustifolia or Lavender (Faydal1 et al., 2018). Originally, it has been used mostly in enhancing sleep among patients suffering from insomnia (Nasiri Lari et $a l ., 2020)$. It has been used in many medical and surgical conditions associated with pain. Thus, it proved to be effective in relieving the pain among patients with acute conditions such as burns (Daneshpajooh et al., 2019), as well as chronic conditions like knee osteoarthritis (Nasiri et al., 2016), and hemodialysis (Ahmady et al., 2019). It also showed good effectiveness for surgical pain relief (Franco et al., 2016; Fazlollahpour-Rokni et al., 2019), in nursing interventions (Yayla \& Ozdemir, 2019), as well as in dental practice (Aafaque, 2019; Arslan et al., 2020).

In obstetrics and gynecology, the use of Lavender oil demonstrated good effectiveness in a wide spectrum of conditions. Thus, it was effective in the relief of the pain associated with primary dysmenorrhea (Nikjou et al., 2016). It also improved the quality of life of postmenopausal women (Bakhtiari et al., 2019). In obstetrics, the use of Lavender oil showed success in reducing the duration of labor as well as the associated anxiety and pain (Yazdkhasti \& Pirak, 2016; Hamdamian et al., 2018).

Although the literature abounds with research assessing the effectiveness of Lavender in the relief of pain due to a multitude of medical and surgical 
conditions, in addition to its use in obstetrics, there is a paucity of studies addressing its effectiveness in the relief of post-cesarean section pain.

\section{Aim of the study}

The aim of this study was to investigate the effectiveness of inhalation of Lavender oil in relieving post-cesarean section pain. The research hypothesis was that the pain scores will be significantly lower among women after cesarean section in comparison with women receiving routine care.

\section{METHODOLOGY}

Design and setting: A quasi-experimental design with control group was used in carrying out the study at the Postpartum Unit affiliated to Suez-Canal University Hospitals. It is a main governmental specialized center providing maternity care services for women from various social backgrounds and is also a referral center for high-risk mothers.

Subjects: The study was conducted on a convenience sample of 100 postpartum women delivered by cesarean section (CS). They were selected according to the inclusion criteria of being 21-35 years old, at 37- 42 gestational weeks, with 0-3 parity, and within 48 hours of having a CS with spinal anesthesia, and six hours after recovery from anesthesia. Women with any medical and/or obstetric health problems were excluded.

The 100 selected women were randomly divided into two equal groups. The study group consisted of 50 women who were to receive Lavender oil and oxygen to relieve their postoperative pain, in addition to routine hospital care. The control group included 50 women who received only oxygen for management of postoperative pain in addition to routine hospital care. The sample size was calculated to detect an improvement in the scores of women's pain with a moderate effect size (0.60) based on Hulley et al., (2013), using a 1.0 standard deviation at $95 \%$ level of confidence and $80 \%$ power. Accordingly, the required sample size was 45 women per group. This was increased to 50 women per group to compensate for an expected dropout rate of around $10 \%$.

Data collection tools: An interview questionnaire sheet with two pain assessment scales, namely the Visual Analogue Scale (VAS), and the Modified Version of Johansson Pain-O-Meter (MJPOM), was used to collect the necessary data. The questionnaire involved a section for woman's demographic characteristics as age, education level, job, and residence. A second section covered the history of current pregnancy, ante- natal care (ANC), etc. The third section assessed the factors affecting the intensity of pain such as the perception of pain intensity, level of pain tolerance, and knowledge about pain relief methods.

The Visual Analogue Scale (VAS) is a standardized self-report tool developed by Katz \& Melzack (1999) for measuring pain intensity. It consists of a horizontal line divided into a 10-centimeter numerical scale corresponding to the degree of pain from "zero" indicating "no pain" to " 10 " indicating the worst intolerable level of pain, i.e. a higher score indicates more severe pain. For categorical analysis, zero indicates no pain, 1-3 indicates mild pain, 4-6 moderate pain, 7-9 severe pain, and 10 the worst pain. It is a validated tool for assessment of acute and chronic pain (Delgado et al., 2018).

The Modified Version of Johansson Pain-O-Meter (MJPOM) was developed and validated by GastonJohansson (1996) to measure the intensity of affective and sensory components of pain. It is composed of 15 sensory (as stinging, cutting, etc.) and 11 affective (as nagging, torturing, etc.) pain word descriptors. Each word in each component indicates a pain severity ranging from one to five. The woman's choice of words is scored to determine the pain intensity for each component. For each woman, the scores of affective and sensory components are added to provide a total MJPOM score ranging from 2 to 10 , with a higher score indicating a more severe pain. These scores are then categorized into mild pain $(<4)$, moderate pain $(4-6)$, severe pain (7-9), and worst pain (10).

The tools used in data collection are standardized validated tools. A pilot study was conducted on 10 women to test the feasibility of the study and applicability of the tool, and to find out the possible obstacles and problems that might face the researcher during the fieldwork. The women in the pilot study were not included in the main study sample.

Fieldwork: Upon obtaining all required official permissions, the researcher started the process of recruitment of the women according to the eligibility criteria set. The purpose of the study and its maneuver were explained to each one, and those who agreed to participate signed a written informed consent form. The women were consecutively assigned to either the study or the control group.

Study maneuver: The study group women were interviewed using the designed questionnaire form. The woman was under routine treatment of the hospital for post-cesarean pain relief. After six hours, one cc of Lavender oil (bought from a Factory established under 
supervision of the Ministry of Health, registration No. 108/2008) was applied with a cotton swab to the inside of an oxygen face mask. It was inhaled by the woman for three minutes. Then the incisional pain level was assessed after half an hour using the two pain assessment scales (VAS and MJPOM). The woman was also asked about her opinion regarding the effect of Lavender oil in relieving her post-cesarean pain. The control group women were subjected exactly to the same process except for the exposure to Lavender oil in their oxygen mask, and for their opinion about the effect of lavender. The work was done three days per week over a period of four months from October 2013 to January 2014.

Administrative and ethical issues: Written approvals were obtained from Ismailia University Hospital Administration and from the head of the concerned department using official channels. The study protocol was approved by the Research and Ethics Committee at the Faculty of Nursing, Suez Canal University. All research ethics principles were followed according to Helsinki Declaration. All aspects of informed consents, voluntary participation, confidentiality, anonymity, and beneficence were abided by. The study maneuver could not entail any harmful effects on participants.

Statistical analysis: Data entry and statistical analysis were done using SPSS 20.0 statistical software package. Data were presented using descriptive statistics in the form of frequencies and percentages for categorical variables, and means and standard deviations for quantitative variables. Quantitative continuous data were compared using independent Student $t$-test. Qualitative categorical variables were compared using chi-square or Fisher exact test as suitable. Statistical significance was considered at $p$-value $<0.05$.

\section{RESULTS}

As illustrated in Table 1, women in the study and control groups had similar demographic characteristics, with no statistically significant differences. Their age was mostly in the category 21-25 years. Approximately one-third of them were illiterate. Slightly more women in the study group were from urban areas (54.0\%). All women in the two groups were housewives except for 2 $(4.0 \%)$ in the control group.

Table 1: Demographic characteristics of post-cesarean women in the study and control groups

\begin{tabular}{|c|c|c|c|c|c|c|}
\hline \multirow[t]{2}{*}{ Items } & \multicolumn{2}{|c|}{$\begin{array}{l}\text { Study group } \\
\quad(n=50)\end{array}$} & \multicolumn{2}{|c|}{$\begin{array}{l}\text { Control group } \\
(n=50)\end{array}$} & \multirow{2}{*}{$\begin{array}{l}\text { Chi- } \\
\text { Square } \\
\text { Test }\end{array}$} & \multirow[t]{2}{*}{$p$-value } \\
\hline & No & $\%$ & No & $\%$ & & \\
\hline \multicolumn{5}{|l|}{ Age: } & \multirow{5}{*}{$\begin{array}{c}0.664 \\
t=1.216\end{array}$} & \\
\hline $21-25$ & 22 & 44.0 & 22 & 44.0 & & \multirow{4}{*}{$\begin{array}{l}0.718 \\
0.227\end{array}$} \\
\hline $26-30$ & 15 & 30.0 & 18 & 36.0 & & \\
\hline $31-35$ & 13 & 26.0 & 10 & 20.0 & & \\
\hline Mean \pm SD & \multicolumn{2}{|c|}{$27.2 \pm 4.4$} & \multicolumn{2}{|c|}{$26.2 \pm 3.8$} & & \\
\hline \multicolumn{7}{|l|}{ Education: } \\
\hline Illiterate & 16 & 32.0 & 15 & 30.0 & \multirow{4}{*}{1.202} & \multirow{4}{*}{0.753} \\
\hline Basic & 13 & 26.0 & 15 & 30.0 & & \\
\hline Secondary & 18 & 36.0 & 19 & 38.0 & & \\
\hline University & 3 & 6.0 & 1 & 2.0 & & \\
\hline \multicolumn{7}{|l|}{ Job: } \\
\hline Employed & 0 & 0.0 & 2 & 4.0 & \multirow[t]{2}{*}{ Fisher } & \multirow[t]{2}{*}{0.500} \\
\hline Housewife & 50 & 100.0 & 48 & 96.0 & & \\
\hline \multicolumn{7}{|l|}{ Residence: } \\
\hline Rural & 23 & 46.0 & 28 & 56.0 & \multirow[t]{2}{*}{0.640} & \multirow[t]{2}{*}{0.420} \\
\hline Urban & 27 & 54.0 & 22 & 44.0 & & \\
\hline
\end{tabular}


Table 2 shows that only $16.0 \%$ and $18.0 \%$ of the women in the study and control groups were primiparas. They had almost equal gestational weeks, 38.9 and 38.6 weeks respectively. The majority in both groups had regular antenatal care, and from the first trimester. Slightly more women in the control group reported their current pregnancy was wanted $(82.0 \%)$. No statistically significant differences were revealed in women's obstetric data.

Table 2: Obstetric characteristics of post-cesarean women in the study and control groups

\begin{tabular}{|c|c|c|c|c|c|c|}
\hline \multirow[t]{2}{*}{ Items } & \multicolumn{2}{|c|}{$\begin{array}{l}\text { Study group } \\
\quad(\mathrm{n}=50)\end{array}$} & \multicolumn{2}{|c|}{$\begin{array}{l}\text { Control group } \\
\qquad(\mathrm{n}=50)\end{array}$} & \multirow{2}{*}{$\begin{array}{l}\text { Chi- } \\
\text { Square } \\
\text { Test }\end{array}$} & \multirow[t]{2}{*}{$p$-value } \\
\hline & No & $\%$ & No & $\%$ & & \\
\hline \multicolumn{7}{|l|}{ Parity: } \\
\hline 1 & 8 & 16.0 & 9 & 18.0 & \multirow{3}{*}{2.934} & \multirow{3}{*}{0.231} \\
\hline 2 & 11 & 22.0 & 18 & 36.0 & & \\
\hline 3 & 31 & 62.0 & 23 & 46.0 & & \\
\hline \multicolumn{7}{|l|}{ Gestational weeks: } \\
\hline $38-39$ & 20 & 40.0 & 25 & 50.0 & \multirow{3}{*}{$\begin{array}{c}0.650 \\
t=1.427\end{array}$} & \multirow{3}{*}{$\begin{array}{l}0.421 \\
0.157\end{array}$} \\
\hline $40-42$ & 30 & 60.0 & 25 & 50.0 & & \\
\hline Mean \pm SD & & $=1.1$ & & & & \\
\hline \multicolumn{7}{|l|}{ Had regular antenatal care (ANC): } \\
\hline Yes & 42 & 84.0 & 44 & 88.0 & \multirow[b]{2}{*}{0.083} & \multirow[b]{2}{*}{0.773} \\
\hline No & 8 & 16.0 & 6 & 12.0 & & \\
\hline \multicolumn{7}{|l|}{ ANC start: } \\
\hline First trimester & 46 & 92.0 & 43 & 86.0 & \multirow{3}{*}{3.101} & \multirow{3}{*}{0.212} \\
\hline Second trimester & 4 & 8.0 & 4 & 8.0 & & \\
\hline Third trimester & 0 & 0.0 & 3 & 6.0 & & \\
\hline \multicolumn{7}{|l|}{ Wanted pregnancy: } \\
\hline Yes & 34 & 68.0 & 41 & 82.0 & \multirow[t]{2}{*}{2.613} & \multirow[t]{2}{*}{0.106} \\
\hline No & 16 & 32.0 & 9 & 18.0 & & \\
\hline
\end{tabular}

Regarding women's pain perception before the maneuver, Table 3 indicates that $64.0 \%$ of women in the control group were feeling severe pain compared with $50.0 \%$ of those in the study group, but the difference was not statistically significant. They had almost equal pain tolerance, and the majority had no knowledge of the pain relief means after CS. 
Table 3: Pain feeling, tolerance, and awareness among post-cesarean women in the study and control groups

\begin{tabular}{|c|c|c|c|c|c|c|}
\hline \multirow[t]{2}{*}{ Variables } & \multicolumn{2}{|c|}{$\begin{array}{l}\text { Study group } \\
(\mathrm{n}=50)\end{array}$} & \multicolumn{2}{|c|}{$\begin{array}{l}\text { Control group } \\
\quad(n=50)\end{array}$} & \multirow{2}{*}{$\begin{array}{c}\text { Chi- } \\
\text { Square } \\
\text { Test }\end{array}$} & \multirow[t]{2}{*}{$p$-value } \\
\hline & No & $\%$ & No & $\%$ & & \\
\hline \multicolumn{7}{|l|}{ Feeling of pain sensation: } \\
\hline Mild & 4 & 8.0 & 0 & 0.0 & \multirow{3}{*}{5.08} & \multirow{3}{*}{0.079} \\
\hline Moderate & 21 & 42.0 & 18 & 36.0 & & \\
\hline Severe & 25 & 50.0 & 32 & 64.0 & & \\
\hline \multicolumn{7}{|l|}{ Pain tolerance: } \\
\hline Tolerable & 21 & 42.0 & 25 & 50.0 & \multirow[b]{2}{*}{0.644} & \multirow[b]{2}{*}{0.422} \\
\hline Intolerable & 29 & 58.0 & 25 & 50.0 & & \\
\hline \multicolumn{7}{|c|}{ Know about pain relief means after CS: } \\
\hline No & 45 & 90.0 & 42 & 84.0 & \multirow[b]{2}{*}{0.796} & \multirow[b]{2}{*}{0.372} \\
\hline Yes & 5 & 10.0 & 8 & 16.0 & & \\
\hline \multicolumn{7}{|l|}{ Sources of knowledge: } \\
\hline Family & 3 & 6.0 & 2 & 4.0 & & \\
\hline Health team & 2 & 4.0 & 5 & 10.0 & & \\
\hline Study & 0 & 0.0 & 1 & 2.0 & & \\
\hline
\end{tabular}

As Table 4 demonstrates, the women in the study group were having either mild $(16.0 \%)$ or moderate $(70.0 \%)$ VAS pain grades. On the other hand, the women in the control group were having either severe $(22.0 \%)$ or very severe (60.0\%) VAS pain grades. Moreover, the mean pain score was almost double in the control group compared with the study group. These differences were statistically significant $(p<0.001)$.

Table 4: Visual Analog Scale (VAS) pain sensation among post-cesarean women in the study and control groups

\begin{tabular}{|c|c|c|c|c|c|c|}
\hline \multirow[t]{2}{*}{ Pain sensation (VAS) } & \multicolumn{2}{|c|}{$\begin{array}{l}\text { Study group } \\
\quad(n=50)\end{array}$} & \multicolumn{2}{|c|}{$\begin{array}{l}\text { Control group } \\
\qquad(n=50)\end{array}$} & \multirow{2}{*}{$\begin{array}{c}\text { Chi- } \\
\text { Square } \\
\text { Test }\end{array}$} & \multirow[t]{2}{*}{$p$-value } \\
\hline & No & $\%$ & No & $\%$ & & \\
\hline \multicolumn{7}{|l|}{ Pain (VAS) grades: } \\
\hline Mild & 8 & 16.0 & 0 & 0.0 & \multirow{4}{*}{51.960} & \multirow{4}{*}{$<0.001 *$} \\
\hline Moderate & 35 & 70.0 & 9 & 18.0 & & \\
\hline Severe & 6 & 12.0 & 11 & 22.0 & & \\
\hline Very severe/worst & 1 & 2.0 & 30 & 60.0 & & \\
\hline Scores $($ mean \pm SD): $\max =10$ & \multicolumn{2}{|c|}{$4.04 \pm 1.37$} & \multicolumn{2}{|c|}{$7.40 \pm 2.15$} & $t=9.319$ & $<0.001 *$ \\
\hline
\end{tabular}

(*) Statistically significant at $p<0.05$

Regarding the MJPOM pain scale, Table 5 shows that less women in the study group were having severe (cutting, tearing, sharp) sensory (8.0\%) and affective (torturing, killing, suffocating, terrifying) pain (10.0\%) in comparison with $30.0 \%$ and $36.0 \%$ of those in the control group. Moreover, in total MJPOM pain grade, $22.0 \%$ of the women in the study group were having either mild or moderate, compared with none $(0.0 \%)$ of the women in the control group. Additionally, the mean MJPOM pain scores (sensory, affective, and total) were all higher in the control group compared with the study group. All these differences were statistically significant $(p<0.001)$. 
Table 5: Modified Version of Johansson Pain-O-Meter (MJPOM) sensation among post-cesarean women in the study and control groups

\begin{tabular}{|c|c|c|c|c|c|c|}
\hline \multirow[t]{2}{*}{ Pain sensation (MJPOM) } & \multicolumn{2}{|c|}{$\begin{array}{l}\text { Study } \\
\text { group } \\
(\mathrm{n}=50)\end{array}$} & \multicolumn{2}{|c|}{$\begin{array}{l}\text { Control } \\
\text { group } \\
(n=50)\end{array}$} & \multirow{2}{*}{$\begin{array}{c}\text { Chi- } \\
\text { Square } \\
\text { Test }\end{array}$} & \multirow[t]{2}{*}{$p$-value } \\
\hline & No & $\%$ & No & $\%$ & & \\
\hline \multicolumn{7}{|l|}{ Sensory: } \\
\hline Stinging (2) & 11 & 22.0 & 0 & 0.0 & \multirow{4}{*}{29.58} & \multirow{4}{*}{$<0.001^{*}$} \\
\hline Gnawing/Pinching (3) & 32 & 64.0 & 19 & 38.0 & & \\
\hline Burning/Cramping/Pressing/aching (4) & 3 & 6.0 & 16 & 32.0 & & \\
\hline Cutting/tearing/sharp (5) & 4 & 8.0 & 15 & 30.0 & & \\
\hline Scores $($ mean $\pm \mathrm{SD})$ : $\max =5$ & \multicolumn{2}{|c|}{$2.50 \pm 0.78$} & \multicolumn{2}{|c|}{$3.42 \pm 0.83$} & $t=5.711$ & $<0.001^{*}$ \\
\hline \multicolumn{7}{|l|}{ Affective: } \\
\hline Nagging (1) & 11 & 22.0 & 0 & 0.0 & \multirow{5}{*}{35.12} & \multirow{5}{*}{$<0.001^{*}$} \\
\hline Irritating (2) & 2 & 4.0 & 0 & 0.0 & & \\
\hline Troublesome/tiring (3) & 32 & 64.0 & 20 & 40.0 & & \\
\hline Dreadful/fearful (4) & 0 & 0.0 & 12 & 24.0 & & \\
\hline Torturing/killing/suffocating/terrifying (5) & 5 & 10.0 & 18 & 36.0 & & \\
\hline Scores $($ mean \pm SD): $\max =5$ & \multicolumn{2}{|c|}{$2.22 \pm 1.13$} & \multicolumn{2}{|c|}{$3.46 \pm 0.88$} & $t=6.122$ & $<0.001^{*}$ \\
\hline \multicolumn{7}{|l|}{ Total MJPOM: } \\
\hline Mild & 5 & 10.0 & 0 & 0.0 & \multirow{5}{*}{29.86} & \multirow{5}{*}{$<0.001^{*}$} \\
\hline Moderate & 6 & 12.0 & 0 & 0.0 & & \\
\hline Severe & 32 & 64.0 & 19 & 38.0 & & \\
\hline Very severe & 2 & 4.0 & 14 & 28.0 & & \\
\hline Worst & 5 & 10.0 & 17 & 34.0 & & \\
\hline Scores $($ mean \pm SD): $\max =10$ & \multicolumn{2}{|c|}{$4.72 \pm 1.91$} & \multicolumn{2}{|c|}{$6.88 \pm 1.71$} & $t=5.958$ & $<0.001 *$ \\
\hline
\end{tabular}

(*) Statistically significant at $p<0.05$

Examining the relations between the pain scores and study group women's characteristics (Table 6) revealed that the only statistically significant association $(p<0.001)$ was with their parity. It can be noticed that the pain scores were higher among primiparas compared with multiparous. This was true for both the VAS and the MJPOM scales. 
Table 6: Relations between MJPOM and VAS pain sensation and study group post-cesarean women's characteristics

\begin{tabular}{|c|c|c|c|c|c|c|}
\hline \multirow{3}{*}{ Selected variables } & \multicolumn{6}{|c|}{ Pain scale scores $(\max =10)$} \\
\hline & \multicolumn{3}{|c|}{ MJPOM } & \multicolumn{3}{|c|}{ VAS } \\
\hline & Mean \pm SD & $t$-test & $p$-value & Mean \pm SD & $t$-test & $p$-value \\
\hline \multicolumn{7}{|l|}{ Education: } \\
\hline Illiterate $(n=16)$ & $3.63 \pm 1.31$ & \multirow[b]{2}{*}{1.243} & \multirow[b]{2}{*}{0.220} & $4.25 \pm 1.00$ & \multirow[b]{2}{*}{0.115} & \multirow[b]{2}{*}{0.909} \\
\hline Educated $(n=34)$ & $4.24 \pm 2.13$ & & & $3.94 \pm 1.52$ & & \\
\hline \multicolumn{7}{|l|}{ Pregnancy wanted: } \\
\hline Yes $(n=34)$ & $4.12 \pm 2.01$ & \multirow[b]{2}{*}{0.422} & \multirow[b]{2}{*}{0.674} & $4.00 \pm 1.39$ & \multirow[b]{2}{*}{0.311} & \multirow[b]{2}{*}{0.758} \\
\hline No $(n=16)$ & $3.88 \pm 1.54$ & & & $4.13 \pm 1.36$ & & \\
\hline \multicolumn{7}{|l|}{ ANC: } \\
\hline Yes $(n=42)$ & $4.00 \pm 1.98$ & \multirow[b]{2}{*}{0.334} & \multirow[b]{2}{*}{0.739} & $4.00 \pm 0.99$ & \multirow[b]{2}{*}{0.320} & \multirow[b]{2}{*}{0.750} \\
\hline No $(n=8)$ & $4.25 \pm 1.67$ & & & $3.75 \pm 1.67$ & & \\
\hline \multicolumn{7}{|l|}{ Parity: } \\
\hline Primiparous $(\mathrm{n}=8)$ & $5.50 \pm 2.07$ & \multirow[b]{2}{*}{2.471} & \multirow[b]{2}{*}{$0.017^{*}$} & $6.00 \pm 1.85$ & \multirow[b]{2}{*}{3.490} & \multirow[b]{2}{*}{$<0.001^{*}$} \\
\hline Multiparous $(n=42)$ & $3.76 \pm 1.78$ & & & $3.67 \pm 0.87$ & & \\
\hline
\end{tabular}

As displayed in Figure 1, slightly more than twothirds $(68.0 \%)$ of the women in the study group reported that the use of Lavender was effective in decreasing their post-cesarean pain.

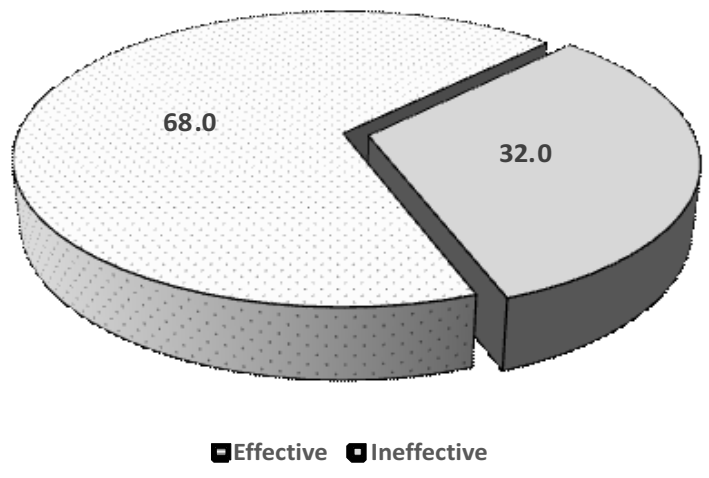

Figure 1: Effect of using lavender on pain sensation as reported by study group post-cesarean women

\section{DISCUSSION}

The study results indicate that the administration of Lavender oil to the women delivered by cesarean section is effective in relieving their postoperative pain. This was demonstrated using two different types of pain assessment scales, in addition to women's opinions. The findings lead to acceptance of the set research hypothesis.

According to the current study findings, the women in the study and control groups had similar demographic as well as obstetric characteristics. This indicates a close similarity in the factors that might influence their pain sensation. This is quite important in assessing the effect of any intervention to improve the internal validity of the study. It is of particular importance in the present study due the use of a quasi-experimental design rather than a randomized clinical trial. This last design is the best in the elimination of any confounders that may influence the effect of the intervention. However, it was not used in our study due to logistic obstacles, and this might be considered as one of the study limitations given the threats to internal validity associated with the quasiexperimental designs as clarified by Flannelly et al., (2018).

Other factors that might influence the pain sensation 
are the level of pain before the maneuver, the perception of the pain and its tolerance, as well as the awareness of the various approaches to relieve it. These factors were taken into consideration in the present study and were found to be similar among women in the study and control groups. In congruence with this, a randomized clinical trial examining the effect of Chamomile oil inhalation on post-cesarean section pain among Iranian women highlighted the similarity of pre-intervention pain perception in the intervention and control groups; the study findings revealed significantly decreased pain levels among the women in the intervention group compared with the placebo control group (Zardosht et al., 2020).

In the present study, the mean VAS pain scores among the women in the study group were around 4, indicating moderate level. In the control group, it was above seven, indicating a severe degree of pain. This points to significantly lower levels of pain that could be attributed to the inhalation of Lavender in the study group. The findings are in agreement with those of a randomized clinical trial conducted by Abbasijahromi et al. (2019) in Iran, where the severity of post-cesarean section pain as measured by the VAS scale was significantly lower among the women who were exposed to Lavender inhalation as compared with control women.

As regards the MJPOM pain scores, the current study results demonstrated that the means for the sensory and affective components were almost equal in each of the two groups. As for the total score, it was slightly more than 4 among the women in the study group, still indicating moderate level, while in the control group, it was almost seven, indicating a severe degree of pain. In congruence with such improvement of pain in the study group, a systematic review demonstrated that aromatherapy proved to be effective in reducing postcesarean-delivery pain, in addition to post-cesareandelivery nausea; moreover, it had no side effects of importance (Tsai et al., 2019).

In addition to assessing the pain using the VAS and
MJPOM scales in the present study, the women in the study group were asked about their opinions regarding the effectiveness of this approach in relieving their pain. The results demonstrated that around two-thirds of them viewed it as effective. This is of great importance since the belief in the analgesic effect of a medication or an approach constitutes an essential part of its success in pain relief. The importance of assessing women' satisfaction with the non-pharmacological approaches to childbirth pain relief was shown in studies in Turkey (Unalmis Erdogan et al., 2017) and Gambia (Colley et al., 2018).

Lastly, concerning the factors that might influence the pain sensation among the women who received the Lavender treatment, the current study showed that only the parity had a significant influence. Thus, the primiparas were having significantly higher VAS and MJPOM pain scores. This is quite plausible given that this is their first experience with labor. The findings are in line with a study carried out in Sweden, where primiparas were found to use more analgesics for labor pain relief, reflecting more experience of pain (Westergren et al., 2020).

\section{CONCLUSION}

The use of Lavender oil inhalation is effective in relieving post-cesarean section pain. It can be used as a safe non-pharmacological therapy with no potential side effects.

\section{Recommendations}

However, a duplication of this study using a full randomized clinical trial design is recommended to provide a stronger evidence of its effectiveness and to overcome the limitations of the quasi-experimental design concerning internal validity.

\section{Conflict of Interests}

The author declare that they have no conflict of interest.

\section{ACKNOWLEDGEMENT}

The authors are thankful to the institutional authority for completion of the work.

\section{REFERENCES}

Aafaque, S. (2019). Effect of Aromatherapy on Dental Anxiety Among Orthodontic Patients: A Randomized Controlled Trial. Cureus, 11(8), e5306.

Abbasijahromi, A., Hojati, H., Nikooei, S., Jahromi, H.K., Dowlatkhah, H.R., Zarean, V., Farzaneh, M. \& Kalavani, A. (2019). Compare the effect of aromatherapy using lavender and Damask rose essential oils on the level of anxiety 
and severity of pain following C-section: A double-blinded randomized clinical trial. Journal of Complementary and Integrative Medicine, [Epub ahead of print]

Ahmady, S., Rezaei, M. \& Khatony, A. (2019). Comparing effects of aromatherapy with lavender essential oil and orange essential oil on fatigue of hemodialysis patients: A randomized trial. Complementary Therapies in Clinical Practice, 36, pp 64-68.

Arslan, I., Aydinoglu, S. \& Karan, N. B. (2020). Can lavender oil inhalation help to overcome dental anxiety and pain in children? A randomized clinical trial. European Journal of Pediatrics, 179(6), pp 985-992.

Bakhtiari, S., Paki, S., Khalili, A., Baradaranfard, F., Mosleh, S. \& Jokar, M. (2019). Effect of lavender aromatherapy through inhalation on quality of life among postmenopausal women covered by a governmental health center in Isfahan, Iran: A single-blind clinical trial. Complementary Therapies in Clinical Practice, 34, pp 46-50.

Colley, S., Kao, C.H., Gau, M. \& Cheng, S.F. (2018). Women's perception of support and control during childbirth in The Gambia, a quantitative study on dignified facility-based intrapartum care. BMC Pregnancy Childbirth, 18(1), pp 413.

Daneshpajooh, L., Najafi Ghezeljeh, T. \& Haghani, H. (2019). Comparison of the effects of inhalation aromatherapy using Damask Rose aroma and the Benson relaxation technique in burn patients: A randomized clinical trial. Burns, 45(5), pp 1205-1214.

Delgado, D.A., Lambert, B.S., Boutris, N., McCulloch, P.C., M.D., Robbins, A.B., Moreno, M.R. \& Harris, J.D. (2018). Validation of Digital Visual Analog Scale Pain Scoring with a Traditional Paper-based Visual Analog Scale in Adults. JAAOS Global Research \& Reviews, 2(3), e088.

Faydal1, S. \& Çetinkaya, F. (2018). The Effect of Aromatherapy on Sleep Quality of Elderly People Residing in a Nursing Home. Holistic Nursing Practice, 32(1), pp 8-16.

Fazlollahpour-Rokni, F., Shorofi, S.A., Mousavinasab, N., Ghafari R. \& Esmaeili R. (2019). The effect of inhalation aromatherapy with rose essential oil on the anxiety of patients undergoing coronary artery bypass graft surgery. Complementary Therapies in Clinical Practice, 34, pp 201-207.

Flannelly, K.J., Flannelly, L.T. \& Jankowski, K.R.B. (2018). Threats to the Internal Validity of Experimental and Quasi-Experimental Research in Healthcare. Journal of Health Care Chaplaincy, 24(3), pp 107-130.

Franco, L., Blanck, T.J., Dugan, K., Kline, R., Shanmugam, G., Galotti, A., von Bergen Granell, A. \& Wajda, M. (2016). Both lavender fleur oil and unscented oil aromatherapy reduce preoperative anxiety in breast surgery patients: a randomized trial. Journal of Clinical Anesthesia, 33, pp 243-9.

Gaston-Johansson, F. (1996). Measurement of pain: the psychometric properties of the Pain-O-Meter, a simple, inexpensive pain assessment tool that could change health care practices. Journal of Pain and Symptom Management, 12(3), pp 172-181.

Hamdamian, S., Nazarpour, S., Simbar, M., Hajian, S., Mojab, F. \& Talebi, A. (2018). Effects of aromatherapy with Rosa damascena on nulliparous women's pain and anxiety of labor during first stage of labor. Journal of Integrative Medicine,16(2), pp 120-125.

Hulley, S.B., Cummings, S.R., Browner, W.S., Grady, D. \& Newman, T.B. (2013). Designing clinical research: an epidemiologic approach. $4^{\text {th }}$ ed. Philadelphia, PA: Lippincott Williams \& Wilkins; Appendix 6A, page 73.

Katz, J. \& Melzack, R. (1999): Measurement of pain. Surgical Clinics of North America, 79(2), pp 231-252.

Nasiri, A., Mahmodi, M.A. \& Nobakht, Z. (2016). Effect of aromatherapy massage with lavender essential oil on pain in patients with osteoarthritis of the knee: A randomized controlled clinical trial. Complementary Therapies in Clinical Practice, 25, pp 75-80. 
Nasiri Lari Z., Hajimonfarednejad M., Riasatian M., Abolhassanzadeh Z., Iraji A., Vojoud M., Heydari M. \& Shams M. (2020). Efficacy of inhaled Lavandula angustifolia Mill. Essential oil on sleep quality, quality of life and metabolic control in patients with diabetes mellitus type II and insomnia. Journal of Ethnopharmacology, 251:112560.

Nikjou R., Kazemzadeh R., Rostamnegad M., Moshfegi S., Karimollahi M. \& Salehi, H. (2016). The Effect of Lavender Aromatherapy on the Pain Severity of Primary Dysmenorrhea: A Triple-blind Randomized Clinical Trial. Annals of Medical and Health Science Research, 6(4), pp 211-215.

Steflitsch, W. (2017). Aromatherapy - From Traditional and Scientific Evidence into Clinical Practice. Deutsche Medizinische Wochenschrift, 142(25), pp 1936-1942.

Tsai, S.S., Wan,g H.H. \& Chou, F.H. (2019). The Effects of Aromatherapy on Postpartum Women: A Systematic Review. The Journal of Nursing Research [Epub ahead of print]

Unalmis Erdogan, S., Yanikkerem, E. \& Goker, A. (2017). Effects of low back massage on perceived birth pain and satisfaction. Complementary Therapies in Clinical Practice, 28, pp 169-175.

Westergren A., Edin K., Lindkvist M. \& Christianson M. (2020). Exploring the medicalisation of childbirth through women's preferences for and use of pain relief. Women and Birth, in press.

Yayla, E.M. \& Ozdemir, L. (2019). Effect of Inhalation Aromatherapy on Procedural Pain and Anxiety After Needle Insertion into an Implantable Central Venous Port Catheter: A Quasi-Randomized Controlled Pilot Study. Cancer Nursing, 42(1), pp 35-41.

Yazdkhasti, M. \& Pirak, A. (2016). The effect of aromatherapy with lavender essence on severity of labor pain and duration of labor in primiparous women. Complementary Therapies in Clinical Practice, 25, pp 81-86.

Zardosht, R., Basir, A., Sahebkar, A. \& Emami S.A. (2020). Effect of chamomile oil on cesarean section pain in primiparous women: a randomized clinical trial. Current Clinical Pharmacology, [Epub ahead of print]

Zeng, Y.S., Wang, C., Ward, K.E. \& Hume, A.L. (2018). Complementary and Alternative Medicine in Hospice and Palliative Care: A Systematic Review. Journal of Pain and Symptom Management, 56(5), pp 781-794.e4. 